\title{
A Brief Analysis of the Training Countermeasures of Mathematical Number Sense in Primary School
}

\author{
$\mathrm{Ge} \mathrm{Xu}{ }^{*}$ \\ Hefei Sanshitou Town Central Primary School, Hefei 230000, China \\ *Corresponding author: Ge Xu, xuge0106@163.com
}

\begin{abstract}
The development of mathematical thinking has steadily become the attention of primary school mathematics teachers as the basic literacy of primary school mathematics. To promote teaching development and further deepen teaching reform, primary school mathematics teachers must change their educational concept, pay attention to the cultivation of students' mathematical thinking in the teaching process, and create an effective teaching classroom with the help of new teaching methods and rich teaching contents. This research examines how primary school mathematics teachers cultivate kids' understanding of numbers and proposes appropriate remedies, with the goal of serving as a model for teachers' teaching improvement.
\end{abstract}

Keywords: Primary school mathematics; Mathematical thinking; Cultivation; Countermeasure

Publication date: December 2021; Online publication: January 24, 2022

\section{Introduction}

The number sense is primarily focused on students' ability to understand the meaning of numbers, express numbers in various ways, master the size relationship of numbers, and calculate the results independently in the primary education stage, according to the mathematics curriculum standard for compulsory education ${ }^{[1]}$. In this light, primary school mathematics teachers must actively change their teaching ideas, focusing on the cultivation of students' sense of number, and introducing diversified teaching methods in conjunction with students' ability development needs, in order to enrich the teaching system and assist students in the process of knowledge learning, realizing the development of self-ability and literacy.

\section{Restrictive factors in cultivating students' sense of number in primary school mathematics}

The integration of new educational concepts and instruction has become the cornerstone to educational reform as the present curriculum reform grows. Some schools and teachers are actively following the educational era's growth and correctly introducing relevant teaching principles into the classroom. However, in the implementation phase, there are more or less the following issues. To begin with, some primary school mathematics teachers have outdated teaching ideas, failing to pay enough attention to the introduction of effective teaching techniques and innovative teaching ideas, and continuing to rely on a single knowledge explanation in teaching, which students must firmly grasp. Students are less likely to participate in activities as a result of boring teaching subject and a single teaching technique, the classroom effect is weak, and students' abilities are not completely developed. Second, in basic literacy, the notion of number sense education is not adequately connected with instruction. Some primary school teachers in the new period aggressively complied with the educational era's growth and began to integrate effective teaching techniques into their teachings, but they did not meet the specified aim. The fundamental cause of this predicament is because teachers' teaching abilities are poor, and they lack the capacity to grasp a variety 
of teaching techniques. In the case of number sense teaching, for example, teachers do not conduct in-depth interpretations of number sense education and instead conduct educational activities based on their own subjective awareness of the new educational concept, but the effect is minimal, resulting in low student interest in participation. The construction goal of an efficient classroom is difficult to achieve.

\section{Research on mathematics teaching reform in primary school under the concept of number sense education}

\subsection{Change the educational thought and focus on the deep integration of number sense and teaching}

Given the current state of primary school mathematics teaching, the author feels that teachers must actively adapt their educational concepts and focus on the integration of new educational ideas and teaching. In order to carry out effective teaching activities and guide students to gradually establish a good consciousness in knowledge learning, teachers must first grasp the actual connotation of the concept of number sense education, then deeply interpret it, analyze the teaching content and students' ability development needs, and consider the coincidence between it and the new teaching concept. We can construct high-quality classrooms, enhance the existing state of education and teaching, and further educational reform in this way. It's worth emphasizing that the teaching topic can be adequately in-depth in order to foster students' subject literacy and help them achieve their educational goals in the new period. Teachers can introduce the method of "combination of number and form" in the teaching of "understanding 10 to 20 " related topics, for example. First and foremost, the teacher will teach the students to prepare 20 sticks in advance of class to help in the formulation of classroom teaching activities. The teacher then instructed the students to count the 13 sticks one by one. This technique can help pupils develop an exploratory mindset ${ }^{[2]}$. During this procedure, the teacher instructed the students to count the sticks in various ways, then allowed them bundle 10 sticks together and count three sticks. Students can clearly understand " 10 ones are one ten," allowing them to develop their mathematical thinking from abstraction to cultivation, which is necessary to ensure students' future learning. Teachers, on the other hand, can enhance the existing state of traditional teaching and achieve the objective of cultivating students' mathematical thinking by altering their educational concepts and focusing on the integration of new teaching techniques, ideas, and strategies.

\subsection{Create a good number sense training situation}

From a practical point of view, there is no lack of knowledge that is difficult to understand and students are difficult to learn actively in primary school mathematics. Furthermore, because primary school students have poor overall cognitive abilities, it is difficult for them to actively participate in the learning process with interest. Furthermore, in order to assist students better understanding in numbers and build digital knowledge, modern mathematical thinking training requires teachers to begin from the perspective of the students' perception. As a result, primary school mathematics teachers must pay close attention to the development of situations in the process of developing students' sense of number. Therefore, allowing the students to actively participate in the learning environment, so that that they can better understand relatively abstract and difficult knowledge. as a result, they can develop their innovative understanding, and that education and teaching can have a greater impact.

For example, in the introductory connection to the teaching of understanding relevant information of "region unit," the learning game of "searching for and comparing" is utilized to create an engaging learning environment. When children leave the classroom for activities, teachers hide certain area units such as digital cards $\left(\mathrm{cm}^{2}, \mathrm{~m}^{2}\right.$, hectares, $\left.\mathrm{km}^{2}\right)$ in every corner. The teacher simply introduced numerous neighborhood acquaintances to the students, told them that these numbers were concealed in the classroom, 
and then rallied everyone to discover them together. The kids instantly organized and tracked down these "neighborhood pals" one by one ${ }^{[3]}$. The teacher then asked the students to consider which unit is the largest if it is larger. Which of the following is a tiny unit? The teacher then instructed the students to line up with various digital cards, tiny units in front and large units in the back, to test whether their sequence was accurate. After assisting the students in mastering these concepts, the teachers engaged them in follow-up teaching activities, and they enthusiastically participated in the learning process.

\subsection{Introduction of life-oriented knowledge}

Primary school mathematics teachers can include real information into their lessons to help students develop a stronger sense of number. We may minimize the gap between life and the classroom by using this measure, which will help students identify the connection between life and learning content, promote students' application consciousness, and allow them to recognize the quantification of the surrounding environment. We can, for example, develop a life-oriented classroom and incorporate students' lifeoriented information in their everyday lives while teaching "mixed operation." To begin, teachers create a supermarket environment for kids, using their pencil cases, pens, and other stationery as goods in the store. Second, pick a random student and tell him what to buy, such as 2 "tomatoes" and 4 "carrots." Then invite the students to calculate independently, with the option for other students to do so as well. Teachers perform a leading role when students make mathematical errors, correcting students' incorrect algorithms as soon as possible. Finally, teach students to summarize hybrid algorithms such as multiplication and division coming before addition and subtraction, brackets coming before brackets, and etc. Students' learning initiative is improved, and the teaching effect is more visible, as a result of the development of engaging learning settings. They can actively participate in the learning process when presented with engaging learning information. Students' application knowledge and perception of numbers develop at the same time, and the teaching effect is substantial. For another example, students might consider where they have seen 0 in their lives when learning about "understanding 0. ." When confronted with this issue, the students were engaged and actively participated in classroom activities. Some claimed to have seen it on the scorer, while others claimed to have seen it on their phones. The instructor then showed the children the thermometer, explained the meaning of 0 to them, and encouraged them to improve their perception skills.

\subsection{Improve education and teaching evaluation}

Mathematics teachers must also pay attention to the overall evaluation of students as part of mathematical thinking learning. Teachers focus on students' successes in traditional education examinations, which leads to students' failure to identify their own learning issues in a timely manner, and teachers' incapacity to completely comprehend students' current learning condition. As a result, teachers should pay attention to students' learning processes, appraise students' classroom engagement, sensitivity to numbers, and application awareness, and help students to identify and rectify their own learning deficits in a timely manner. Following that, teachers must enhance their teaching techniques and material in relation to student evaluation in order to ensure the smooth progression of educational activities.

\section{Conclusion}

To summarize, primary school mathematics teachers must change their educational perspectives and focus on the deep integration of number sense education and teaching, which is conducive to the development of a new teaching system that will assist students in mastering more knowledge and developing their own mathematical thinking consciousness. As a result, primary school mathematics teachers must begin from the bottom up and construct a new classroom teaching environment in conjunction with new teaching 
concepts in order to deepen teaching reform and enhance teaching growth.

\section{Disclosure statement}

The author declares that there is no conflict of interest.

\section{References}

[1] Yang Y, 2021, Research on the Cultivation Strategy of Number Sense in Primary School Mathematics Learning. Scientific Consultation (Education and Scientific Research), 2021(9): 253-255.

[2] Yang Z, 2020, The Cultivation of Mathematical Number Sense in Primary School in Origami - A Comment on Origami and Mathematics. China Paper, 39(7): 113.

[3] Dong C, 2020, Implementation of Mathematics Teaching Strategy in Primary School based on the Cultivation of Number Sense. China New Communications, 22(12): 175. 